\title{
SOME NEW GENERALIZATIONS OF ZYGMUND-TYPE INEQUALITIES FOR POLYNOMIALS
}

\section{A. AZIZ And N. A. RATHER}

Abstract. In this paper, we consider a problem of investigating the dependence of

$$
\left\|P(R z)-\alpha P(r z)+\beta\left\{\left(\frac{R+1}{r+1}\right)^{n}-|\alpha|\right\}\right\|_{p}
$$

on $\|P(z)\|_{p}$ for arbitrary real or complex numbers $\alpha, \beta$ with $|\alpha| \leqslant 1,|\beta| \leqslant 1, R>r \geqslant 1$, $p>0$ and present certain sharp compact generalizations of some well-known Zygmund-type inequalities for polynomials, from which a variety of interesting results follows as special cases.

Mathematics subject classification (2010): 30D15, 41A17.

Keywords and phrases: polynomials, inequalities in the complex domain Zygmund's inequality.

\section{REFERENCES}

[1] N. C. Ankeny and T. J. Rivlin, On a theorm of S. Bernstein, Pacific J. Math. 5 (1955), 849-852.

[2] V. V. ARESTOV, On integral inequalities for trigonometric polynimials and their derivatives, Izv. Akad. Nauk SSSR Ser. Mat. 45 (1981), 3-22 [in Russian]. English translation; Math. USSR-Izv. 18 (1982), 1-17.

[3] A. AzIZ, A new proof and a generalization of a theorem of De Bruijn, Proc. Amer Math. Soc. 106 (1989), 345-350.

[4] A. AzIZ AND N. A. RATHER, $L^{p}$ inequalities for polynomials, Glasnik Matematicki 32 (1997), 3943.

[5] A. AzIZ And N. A. RATHER, On an inequality of S. Bernstein and Gauss-Lucas theorem, Analytic and Geometric inequalities, Kluwer Acad. Pub., 1999, 29-35.

[6] A. AZIZ AND N. A. RATHER, Some compact generalization of Zygmund-type inequalities for polynomials, Nonlinear studies 6 (1999), 241-255.

[7] R. P. BOAS, JR., AND Q. I. RAHMAN, $L^{p}$ inequalities for polynomials and entire functions, Arch. Rational Mech. Anal. 11 (1962), 34-39.

[8] N. G. BRUIJN, Inequalities concerning polynomials in the complex domain, Nederal. Akad. Wetensch. Proc. 50 (1947), 1265-1272.

[9] K. K. Dewan And N. K. Govil, An inequality for self-inversive polynomials, J. Math. Anal. Appl. 45 (1983), 490.

[10] G. H. HARDY, The mean value of the modulus of an analytic function, Proc. London Math. Soc. 14 (1915), 269-277.

[11] V. K. JAIN, Generalization of certain well-known inequalities for polynomials, Glasnik Matematicki 32 (1997), 45-51.

[12] P. D. LAX, Proof of a conjecture of P.Erdös on the derivative of a polynomial, Bull. Amer. Math. Soc. 50 (1944), 509-513.

[13] G. V. Milovanovic, D. S. Mitrinovic and Th. M. Rassias, Topics in Polynomials: Extremal Properties, Inequalities, Zeros, World scientific Publishing Co., Singapore, 1994.

[14] G. Pólya An G. Szegö, Aufgaben und lehrsätze aus der Analysis, Springer-Verlag, Berlin, 1925.

[15] Q. I. Rahman and G. Schmeisser, Les Inequalitués de Markoff et de Bernstein, Presses Univ. Montréal, Montréal, Quebec, 1983. 
[16] Q. I. RAHMAN AND G. SChMESSIER, $L^{p}$ inequalities for polynomials, J. Approx. Theory $\mathbf{5 3}$ (1988), $26-32$.

[17] Q. I. RAhmAn And G. SChmessier, Analytic theory of polynomials, Claredon Press, Oxford, 2002.

[18] M. RIESZ, Formula d'interpolation pour la dérivée d'un polynome trigonométrique, C. R. Acad. Sci, Paris, 158 (1914), 1152-1254.

[19] A. C. SCHAFFER, Inequalities of A. Markoff and S. Bernstein for polynomials and related functions, Bull. Amer. Math Soc. 47 (1941), 565-579.

[20] A. Zygmund, Aremark on conjugate series, Proc. London Math. Soc. 34 (1932), 292-400. 